\title{
Murine Teratology of Fluconazole: Evaluation of Developmental Phase Specificity and Dose Dependence
}

\author{
GIAN M. TIBONI AND FRANCA GIAMPIETRO \\ Sezione di Ostetricia e Ginecologia, Dipartimento di Medicina e Scienze dell'Invecchiamento, Facoltà di \\ Medicina e Chirurgia, Università “G. d'Annunzio,” 66013 Chieti, Italy
} \begin{abstract}
The potential of in utero exposure to fluconazole to initiate
teratogenesis was analyzed in ICR (CD-1) mice. Developmental phase specificity was determined by treating mice with single oral doses of $700 \mathrm{mg} / \mathrm{kg}$ on gestational day $8,9,10,11$, or 12 . Control animals received vehicle on gestational days 8-12. Gestational day 10 was identified as the phase of maximal sensitivity for induction of cleft palate, the predominant teratogenic effect induced by fluconazole, with $50 \%$ of fetuses exposed on this developmental phase being affected. After treatments on gestational day $8,9,11$, or 12 , cleft palate occurred with lower frequencies: $12,21,28.7$, and $2.7 \%$, respectively. Examination of skeletal morphology revealed anomalies of the middle ear appa-
\end{abstract}

ratus in $15 \%$ of the fetuses that were exposed on gestational day 8. Dysmorphic tympanic ring and absence of the incus were the more common ear anomalies recorded. Reduced humeral length was noted in $22 \%$ of fetuses that were exposed on gestational day 10. Dose-response relationship was investigated by treating animals with 0 (vehicle), 87.5, 175, or $350 \mathrm{mg} / \mathrm{kg}$ on gestational day 10 , coincident with the phase of peak teratogenic sensitivity. Besides showing that fluconazole operates under a strict doseresponse mechanism, the study identified $175 \mathrm{mg} / \mathrm{kg}$ as the lowest observed adverse effect level for cleft palate induction, with $7.6 \%$ of the exposed fetuses being affected. (Pediatr Res 58: 94-99, 2005)
Fluconazole, a synthetic azole antifungal agent, was identified recently as a possible human teratogen $(1,2)$. Several congenital anomalies, including craniofacial, limb, kidney, and cardiac defects, have been observed in four children who were exposed prenatally to doses of 400-800 mg/d for several weeks (3-5). It seems feasible that fluconazole becomes teratogenically operative only under high levels of exposure, because no increment in congenital malformations have been reported after exposure to a single dose or multiple doses of 50-200 mg (6-9).

Animal models, in vitro and in vivo, have been used to investigate the teratogenicity of fluconazole. A specific teratogenic effect on the branchial arch apparatus has been described in cultured whole mouse (10) and rat embryos (11-13). The branchial arches are transitional embryonic structures involved in the development of several components of the head and neck. Skeletal derivatives originating from the branchial arch

Received June 8, 2004; accepted October 13, 2004.

Correspondence: Gian Mario Tiboni, M.D., Sezione di Ostetricia e Ginecologia, Dipartimento di Medicina e Scienze, dell'Invecchiamento, Facoltà di Medicina e Chirurgia, Università "G. d'Annunzio," Chieti-Pescara Ospedale "SS. Annunziata" Via dei Vestini, 66013 Chieti, Italy; e-mail: tiboni@unich.it.

Supported by the Italian National Health System Project "Human Exposure to Xenobiotics with Potential Endocrine Activities: Evaluation of Reproduction and Developmental Risks."

DOI: 10.1203/01.PDR.0000166754.24957.73 apparatus include the Meckel's cartilage (around which the membranous bone of the mandible develops), components of the middle ear apparatus, the styloid process, the hyoid bone, and thyroid and cricoid cartilages (14). Two subdivisions of the first branchial arch, termed maxillary and mandibular prominences, give rise to the majority of the upper and lower jaws. Abnormal branchial arch phenotypes induced by fluconazole in cultured rodent embryos included hypoplasia, agenesis, and fusion of the first and second arches (10-13).

Fluconazole has been tested for in vivo teratogenic effects in rats and rabbits $(15,16)$. When pregnant rats were treated with 25 or $125 \mathrm{mg} / \mathrm{kg}$ during days $6-17$ of gestation, an increased occurrence of fetal anatomical variants, including renal pelvis dilation (at $125 \mathrm{mg} / \mathrm{kg}$ ) and supernumerary ribs (at 25 and 125 $\mathrm{mg} / \mathrm{kg}$ ), were noted. Doses ranging from 80 to $320 \mathrm{mg} / \mathrm{kg}$ resulted in increased embryo lethality and in fetal abnormalities, including wavy ribs, cleft palate, and abnormal craniofacial ossification. No evidence of teratogenicity was found after exposure of pregnant rabbits to 5,10 , or $20 \mathrm{mg} / \mathrm{kg}$ during days 7-18 after insemination.

Fluconazole is widely used in the treatment of several types of fungal infections, including common forms such as vaginal candidiasis, and therefore has an elevated potential for human gestational exposure. In view of the limited current characterization of its teratogenic capacity, in the present study, the 
possible noxious consequences of in utero exposure to fluconazole were investigated for the first time in mice. Analysis focused on the effect of developmental stage at exposure on teratogenic susceptibility and dose-response relationship.

\section{METHODS}

Testing drug/dosing solutions. The capsule formulation available for oral administration (Diflucan), which contains $150 \mathrm{mg}$ of fluconazole and lactose $(150 \mathrm{mg})$, corn starch $(49 \mathrm{mg})$, magnesium stearate $(3 \mathrm{mg})$, sodium lauryl sulfate $(0.4 \mathrm{mg})$, and silica precipitate $(0.4 \mathrm{mg})$ as inactive ingredients, was used. Capsule contents were suspended in olive oil and administered by intragastric intubation (gavage) at a dosage volume of $50 \mathrm{~mL} / \mathrm{kg}$. Controls were dosed with vehicle, prepared by suspending appropriate concentrations of the inactive, analytical grade ingredients purchased from Caesar \& Loretz GmbH (Hilden, Germany; magnesium stearate and corn starch) and A.C.E.F. s.p.a (Piacenza, Italy; silica precipitate) in olive oil.

Animal husbandry and breeding procedure. Mature ICR (CD-1) mice (24-26 g) were obtained from Harlan Italy (Udine, Italy). Upon arrival, animals were housed in plastic cages and quarantined for $1 \mathrm{wk}$ before mating Rodent laboratory chow (Harlan Teklad) and tap water were provided ad libitum. During the entire study, animals were kept at the following controlled conditions: temperature of $22 \pm 1{ }^{\circ} \mathrm{C}, 55 \pm 5 \%$ of relative humidity, and a light/dark cycle of $12 \mathrm{~h}$. Three/four females were cohabited overnight with a male of the same stock and examined for vaginal plug (taken as evidence of mating) at the end of the dark cycle (0800). The day when vaginal plug was noted was designated as gestational day 0 . The study was approved by the Institutional Animal Care and Use Committee.

Developmental phase specificity. The influence of the timing of exposure on the teratogenic outcome was investigated by treating pregnant animals with a single high dose of $700 \mathrm{mg} / \mathrm{kg}$ on gestational day $8,9,10,11$, or 12 . These gestational time points are known to encompass major organogenesis in the mouse (14). Controls were treated with vehicle on gestational days 8-12.

Dose-response relationship. Teratogenic dose-response relationship was investigated by administering fluconazole at oral doses of 0 (vehicle), 87.5, 175 , or $350 \mathrm{mg} / \mathrm{kg}$ on gestational day 10 . The timing of exposure was selected on the basis of the information provided by the developmental phasespecificity study showing gestational day 10 as the peak sensitive period for fluconazole-induced teratogenesis.

End-points evaluation. Pregnancies were terminated near term, on gestational day 18 , and the maternal weight, pregnant uterus weight, materna absolute weight (maternal weight - pregnant uterine weight), number of live and dead fetuses, fetal sex, fetal weight, and gross fetal morphologic defects were recorded. Then, one half of the fetuses from each litter were prepared for double-staining skeletal examination using the methods of Inouye (17) and Kimmel and Trammel (18) as modified by Kuczuk and Scott (19). The remainder of the fetuses were fixed in Bouin's solution and subsequently examined for visceral anomalies using the free-hand razor blade sectioning technique according to Wilson (20). All morphologic evaluations were carried out under a stereomicroscope.

Statistical analysis. Continuous data were compared using $t$ test or ANOVA and post hoc Student-Newman-Keuls test for multiple comparisons. Binomial data were compared using the $\chi^{2}$ test or the Fisher's exact test when appropriate. Differences were considered statistically significant at $p<0.05$.

\section{RESULTS}

Developmental phase specificity. Oral treatment with fluconazole at $700 \mathrm{mg} / \mathrm{kg}$ on gestational day $8,9,10,11$, or 12 neither induced clinically evident signs of maternal toxicity nor affected maternal body weight parameters (Table 1). There were no treatment-related effects on the remaining gestational parameters considered, including the number of live fetuses and the mean fetal and placental weights (Table 1).

The timing of exposure was a critical determinant of fluconazole-induced embryo lethality, because only animals that received the drug on gestational day 10 had a significant increase $(p<0.05)$ of the control level of postimplantation loss (from 11.5 to $21 \%$; Fig. 1).

Administration of fluconazole on gestational day $8,9,10$, or 11 resulted in a significant increment $(p<0.05)$ of live fetuses with cleft palate compared with the control group (Fig. 1). The phenotypic appearance of cleft palate is shown in Fig. 2. Gestational day 10 represented the peak sensitivity for cleft palate, with $50 \%$ of fetuses being affected (Fig. 1). Moving backward or forward from this time point resulted in a sharp decrement of cleft palate frequencies (Fig. 1). Indeed, whereas fluconazole administration on gestational day 9 or 11 disrupted palate closure in 21 and $28.7 \%$ of fetuses respectively, treatment on gestational day 8 or 12 , affected only 12.7 and $2.3 \%$ of fetuses, respectively (Fig. 1). There were four (3.17\%) instances of exencephaly among fetuses that were exposed on gestational day 8 (data not shown). Statistical analysis did not reveal this frequency as significant in comparison with controls. Cleft palate (2 of $147 ; 1.36 \%$ ) was the only gross malformation observed in the control group (Fig. 1).

Table 1. Effect of fluconazole* on gestational parameters in the ICR (CD-1) mouse (developmental phase specificity study)

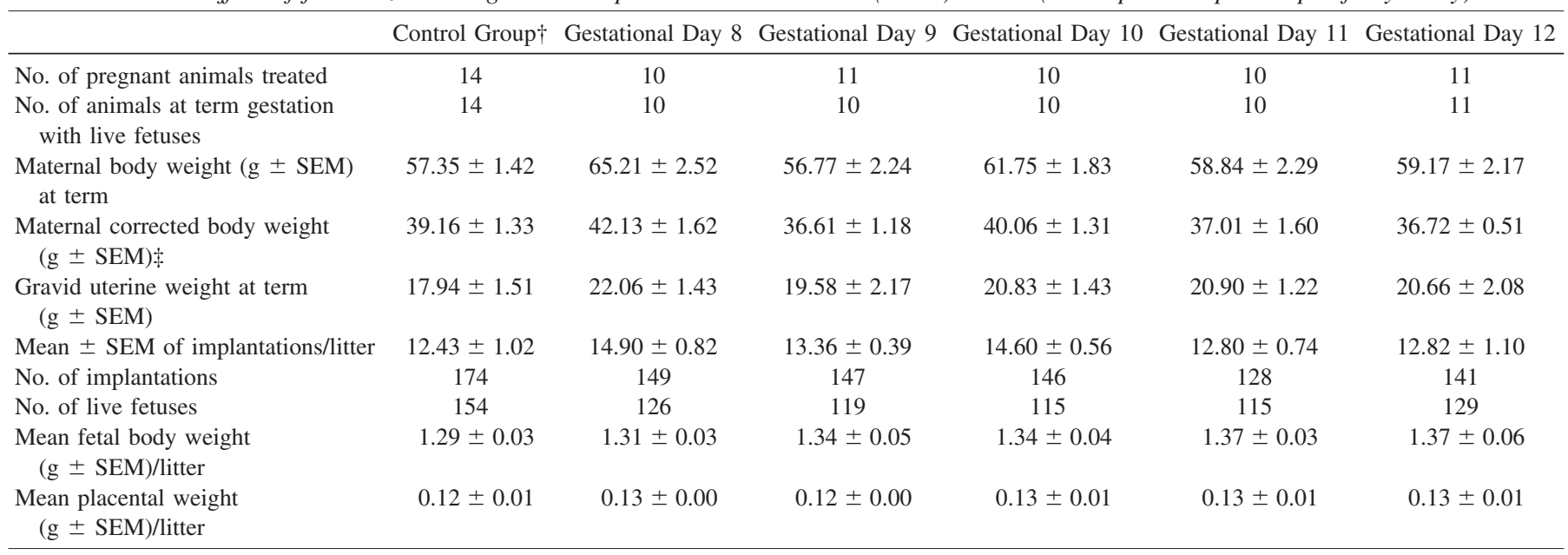

* $700 \mathrm{mg} / \mathrm{kg}$ administered orally.

$\dagger$ Administered with vehicle on gestational days 8-12.

$\ddagger$ Maternal body weight at term minus gravid uterine weight. 


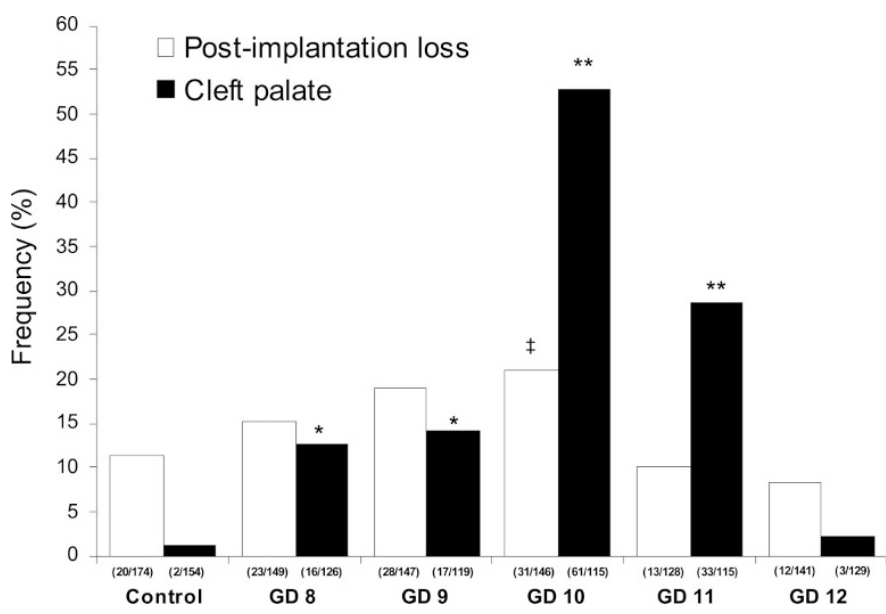

Figure 1. Effect of fluconazole on postimplantation loss and cleft palate in the ICR (CD-1) mouse (stage-specificity study). Fluconazole $(700 \mathrm{mg} / \mathrm{kg}$ ) was administered orally on gestational day $8,9,10,11$, or 12 . Control animals were administered vehicle during gestational days 8-12. Uterine contents were evaluated on gestational day 18. GD, gestational day of treatment. Numbers in parentheses refer to the number of resorbed/dead fetuses of the total number of implants or to the number of affected fetuses of the total number of fetuses examined. $\$$ Statistically significant higher frequency of postimplantation loss of GD 10 (31 of 146) vs control group (20 of 174; $p<0.05 ; \chi^{2}$ test); *statistically significant higher frequencies of cleft palate of GD 8 (16 of 126) and GD 9 (17 of 119) vs control group (2 of 154; $p<0.05 ; \chi^{2}$ test); **statistically significant higher frequencies of cleft palate of GD 10 (61 of 115 ) and GD 11 (33 of 115) vs control group ( 2 of 154), GD 8 (16 of 126), GD 9 (17 of 119 ), and GD 12 (3 of $129 ; p<0.05 ; \chi^{2}$ test).
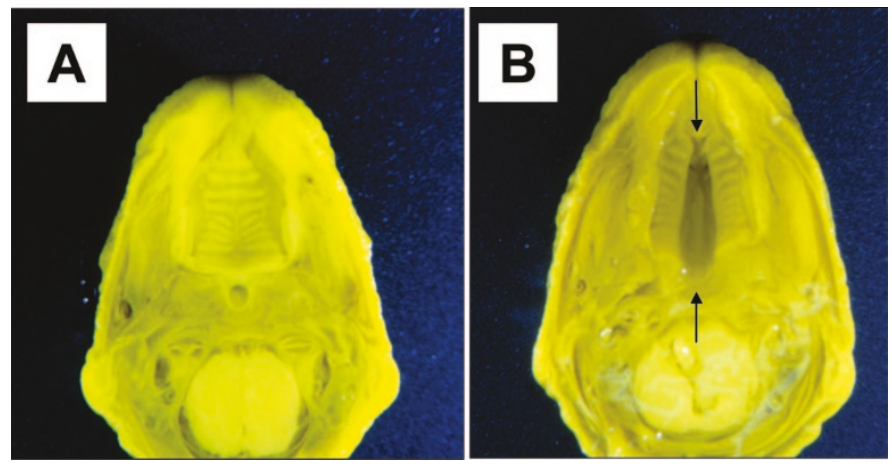

Figure 2. (A) Palate from a control GD 18 mouse fetus. (B) Cleft palate from a GD 18 mouse fetus that was exposed to fluconazole at $700 \mathrm{mg} / \mathrm{kg}$ on GD 10 .

Types and frequencies of skeletal and visceral abnormalities observed in fluconazole-exposed fetuses are shown in Table 2. Evaluation of skeletal morphology revealed treatment-related teratogenic effects on the middle ear apparatus and limbs. These effects were characterized by a strict phase specificity. Defective ears were produced only by gestational day 8 treatments, with $15 \%$ of exposed fetuses being affected. Statistical analysis revealed this frequency as statistically significant $(p=$ 0.002 ) in comparison with the control group. Ear development of the control group was undisturbed. The most frequent ear defects were absence of the incus and dysmorphic tympanic ring. Examples of ear abnormalities are shown in Fig. 3. When fluconazole was given on gestational day $10,22 \%$ of exposed fetuses displayed a shortening of the humerus $(p<0.001$ versus control group; Fig. 4). The administration of fluconazole on gestational day 8,10 , or 11 significantly $(p<0.001)$ increased the frequency of rib variations (including long supernumerary thoracolumbar and short supernumerary thoracolumbar ribs) when compared with the control group.

Examination of visceral morphology revealed a significantly higher frequency $(p=0.007)$ of dilated renal pelvis in fetuses that were exposed on gestational day 10 compared with the control group. No other visceral defects were identified.

Dose-response relationship. Dose-dependence was investigated by treating animals with fluconazole at oral doses of 0 (vehicle), $87.5,175$, or $350 \mathrm{mg} / \mathrm{kg}$ on gestational day 10 . The data obtained were integrated with data resulting from treatment with $700 \mathrm{mg} / \mathrm{kg}$ on gestational day 10 in the developmental phase specificity study. Analysis of external, visceral, and skeletal morphology revealed cleft palate as the only teratogenic response caused by doses $<700 \mathrm{mg} / \mathrm{kg}$. Cleft palate frequencies are provided, along with frequencies relative to postimplantation loss, in Fig. 5. Whereas exposure to 87.5 $\mathrm{mg} / \mathrm{kg}$ resulted in a control-comparable frequency of cleft palate $(1 \%)$, a statistically significant increase of this defect (6.7\%) was induced by treatment with $175 \mathrm{mg} / \mathrm{kg}(p<0.05$ versus control group). Thus, $175 \mathrm{mg} / \mathrm{kg}$ represented the lowest observed adverse effect level (LOAEL) for cleft palate. Consistently with a dose dependence, after treatments with 350 and $700 \mathrm{mg} / \mathrm{kg}$, the frequency of cleft palate increased to 26 and $53 \%$, respectively. Other than cleft palate, no morphologic anomalies were induced by fluconazole at doses ranging from 87.5 to $350 \mathrm{mg} / \mathrm{kg}$, with the exception of an increased frequency of supernumerary ribs seen after fluconazole at 350 $\mathrm{mg} / \mathrm{kg}$ (data not shown). After this treatment regimen, a fivetime increase of the control frequency of this anatomical variation, from 9.7 to $49 \%(p<0.001)$, resulted (data not shown). There were no significant differences in gestational parameters. Gestational parameters of experimental and control groups were comparable (Table 3).

\section{DISCUSSION}

In the present study, a single high dose of fluconazole caused phase-specific teratogenic effects that included cleft palate and middle ear apparatus and limb malformations. Malformations of the middle ear apparatus were observed only after dosing on gestational day 8 , whereas administration on gestational day 10 resulted in limb defects (short humerus). Cleft palate, the most sensitive developmental response induced by fluconazole, showed a broader gestational phase of sensitivity, which encompassed gestational days $8,9,10$, and 11 . However, even regarding cleft palate, the timing of exposure influenced teratogenic outcome, with maximal sensitivity peaking on gestational day 10. Treatment with fluconazole also resulted in a greater number of anatomical variants, including supernumerary ribs (after treatment on gestational days 8,10 , and 11) and renal pelvis dilation (after treatment on gestational day 10). It seems remarkable that fluconazole initiated teratogenesis without affecting the indices of maternotoxicity measured in the study (clinical signs, mortality, and body weight change). This suggests that the developmental adverse effects were not mediated by a maternal imbalance. The hypothesis that flucon- 
Table 2. Type and frequency of skeletal and visceral defects induced by fluconazole* in the ICR (CD-1) mouse at different time points

Control $\dagger$ Gestational Day 8 Gestational Day 9 Gestational Day 10 Gestational Day 11 Gestational Day 12

\begin{tabular}{|c|c|c|c|c|c|c|}
\hline \multicolumn{7}{|l|}{ Skeletal defects } \\
\hline No. of fetuses examined $\ddagger$ & 72 & 65 & 61 & 59 & 59 & 66 \\
\hline $\begin{array}{l}\text { Total no. of fetuses with middle ear } \\
\text { apparatus anomalies }\end{array}$ & 0 & $10(15.38 \%) \|$ & 0 & 0 & 0 & 0 \\
\hline Absent incus & 0 & $6(9.23 \%)$ & 0 & 0 & 0 & 0 \\
\hline Absent malleus & 0 & $2(3.08 \%)$ & 0 & 0 & 0 & 0 \\
\hline Absent stapes & 0 & $2(3.08 \%)$ & 0 & 0 & 0 & 0 \\
\hline Abnormal incus & 0 & $3(4.61 \%)$ & 0 & 0 & 0 & 0 \\
\hline Abnormal malleus & 0 & $1(1.54 \%)$ & 0 & 0 & 0 & 0 \\
\hline Abnormal tympanic ring & 0 & $7(10.78 \%)$ & 0 & 0 & 0 & 0 \\
\hline Total no. of fetuses with limb defects & 0 & 0 & 0 & $13(22.03 \%) \mathbb{I}$ & $1(1.69 \%)$ & $1(1.51 \%)$ \\
\hline Short humerus & 0 & 0 & 0 & $13(22.03 \%)$ & $1(1.69 \%)$ & 0 \\
\hline Short or small phalanx & 0 & 0 & 0 & 0 & 0 & $1(1.51 \%)$ \\
\hline $\begin{array}{l}\text { Total no. of fetuses with abnormal } \\
\text { vertebrae }\end{array}$ & 0 & $2(3.08 \%)$ & $1(1.64 \%)$ & $2(3.40 \%)$ & $4(6.78 \%)$ & $1(1.51 \%)$ \\
\hline Thoracic hemivertebrae & 0 & 0 & $1(1.64 \%)$ & 0 & 0 & 0 \\
\hline Misshapen thoracic vertebrae & 0 & 0 & 0 & $1(1.69 \%)$ & 0 & 0 \\
\hline Misshapen lumbar vertebrae & 0 & $1(1.54 \%)$ & 0 & 0 & $3(5.08 \%)$ & $1(1.51 \%)$ \\
\hline Absent lumbar vertebrae & 0 & 0 & 0 & 0 & $1(1.69 \%)$ & 0 \\
\hline Caudal hemivertebrae & 0 & $1(1.54 \%)$ & 0 & 0 & 0 & 0 \\
\hline Fused caudal vertebrae & 0 & 0 & 0 & $1(1.69 \%)$ & 0 & 0 \\
\hline $\begin{array}{l}\text { Total no. of fetuses with rib } \\
\text { anomalies }\end{array}$ & $7(9.72 \%)$ & $44(67.69 \%) \mathbb{I}$ & $9(14.75 \%)$ & $31(52.54 \%) \mathrm{I}$ & $51(86.44 \%) \mathbb{I}$ & $8(12.12 \%)$ \\
\hline $\begin{array}{l}\text { Long supernumerary } \\
\text { thoracolumbar§ }\end{array}$ & $3(4.16 \%)$ & $37(56.92 \%)$ & $5(8.20 \%)$ & $21(35.59 \%)$ & $28(47.46 \%)$ & $2(3.03 \%)$ \\
\hline $\begin{array}{l}\text { Short supernumerary } \\
\text { thoracolumbar } \$\end{array}$ & $7(9.72 \%)$ & $12(18.46 \%)$ & $7(11.47 \%)$ & $13(22.03 \%)$ & $26(44.07 \%)$ & $8(12.12 \%)$ \\
\hline \multicolumn{7}{|l|}{ Visceral defects } \\
\hline No. of fetuses examined $\ddagger$ & 71 & 54 & 58 & 56 & 55 & 63 \\
\hline $\begin{array}{l}\text { Total no. of fetuses with anomalies } \\
\text { of the urinary tract }\end{array}$ & $1(1.41 \%)$ & $6(11.11 \%)$ & $5(8.62 \%)$ & $9(16.07 \%) \#$ & $8(14.54 \%)$ & $4(6.35 \%)$ \\
\hline Dilated renal pelvis & $1(1.41 \%)$ & $5(9.26 \%)$ & $5(8.62 \%)$ & $9(16.07 \%)$ & $8(14.54 \%)$ & $4(6.35 \%)$ \\
\hline Distended bladder & 0 & $1(1.85 \%)$ & 0 & 0 & 0 & 0 \\
\hline
\end{tabular}

* $700 \mathrm{mg} / \mathrm{kg}$ administered orally.

$\dagger$ Administered with vehicle during gestational days 8-12.

$\ddagger$ A single fetus may be represented more than once in listing individual morphologic abnormalities.

$\S$ Variations.

$\|$ Statistically significant $(p=0.002) v s$ control group.

II Statistically significant $(p<0.001) v s$ control group.

\# Statistically significant $(p=0.007)$ vs control group.

azole acts directly on the embryo is also supported by whole embryo culture findings (10-13).

The middle ear apparatus is composed of three endochondral auditory ossicles (the stapes, incus, and malleus) and the tympanic ring, which is a dermal bone $(21,22)$. The malleus, the incus, and the tympanic ring are derived from the first (mandibular) branchial arch; the stapes are derived from the second (hyoid) branchial arch $(21,22)$. When fluconazole was administered on gestational day $8,15 \%$ of fetuses were found to have abnormal development of middle ear apparatus skeletal components, including incus, malleus, stapes, and tympanic ring. This constellation of fluconazole-induced ear anomalies, described in the present study for the first time, seems to be remarkably consistent with studies carried out using the postimplantation whole embryo culture. Indeed, branchial arch anomalies were the most sensitive teratogenic responses elicited by fluconazole in cultured mouse (10) and rat (11-13) embryos. Studies with rat embryos also led to the postulations that 1 ) an interference with the cellular and molecular mechanisms that control neural crest cell migration may be causal in the elicitation of teratogenic effects $(12,13)$ and 2) the branchial arch abnormalities induced by both fluconazole and retinoic acid in cultured embryos may be the result of a common alteration of the pathogenetic pathway (13). When the teratogenic spectrum induced by fluconazole is considered, it must be noted that not only ear anomalies but also cleft palate can be regarded as a defect having an embryologic relation with deviant branchial arch development, considering that the majority of the secondary palate originates from medial outgrowths of the maxillary prominences of the first branchial $\operatorname{arch}(14)$.

This is not the first study to describe teratogenic effects after in utero exposure to fluconazole. Oral administration of fluconazole to pregnant rats during gestational days 6-17 was associated with several developmental disorders, including an increase in fetal anatomic variants (supernumerary ribs and renal pelvis dilation) and delays in ossification after oral dosages of $25 \mathrm{mg} / \mathrm{kg}$ or greater and increased embryo lethality, cleft palate, and abnormal craniofacial ossification after treatment with $80-320 \mathrm{mg} / \mathrm{kg}$ daily $(15,16)$. This spectrum of 

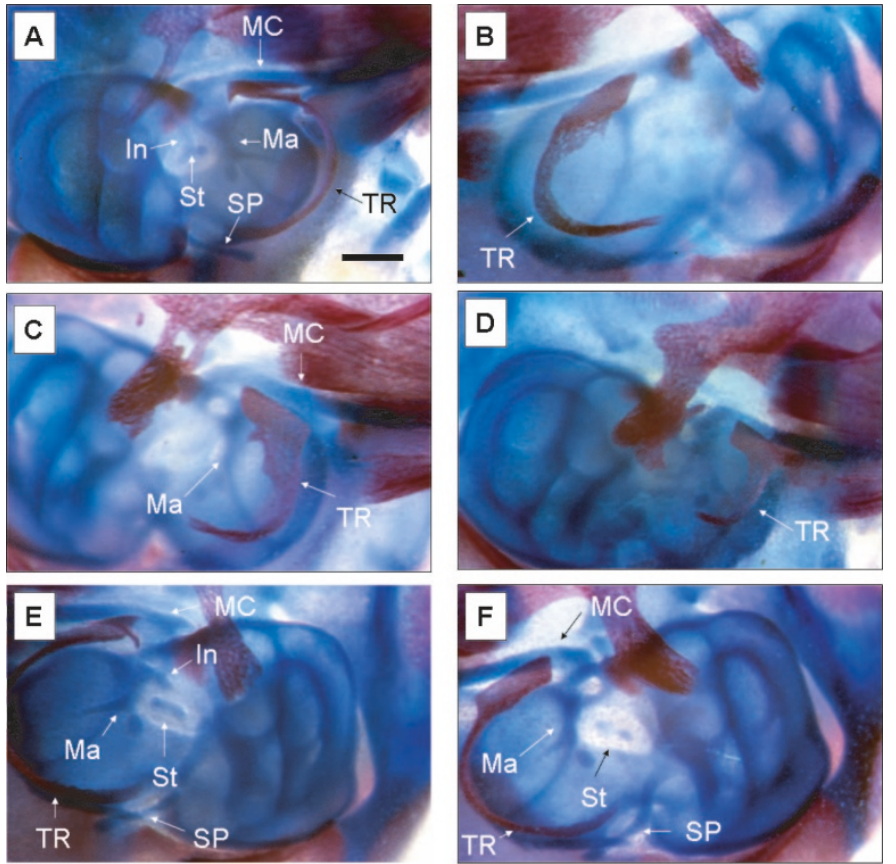

Figure 3. Lateral views of Alcian blue (cartilage) and alizarin red (bone) stainings of ear skeletal components from GD 18 mouse fetuses. MC, Meckel's cartilage; Ma, malleus; In, incus; St, stapes; TR, tympanic ring; SP, styloid process. Bar $=0.5 \mathrm{~mm}$. (A) Right normally developed ear from a control fetus. $(B-F)$ Ear components from fetuses that were exposed to fluconazole at 700 $\mathrm{mg} / \mathrm{kg}$ on GD 8. Note the abnormalities of tympanic rings in $B-D$ and the absence of the incus in $C$ and $F$ and of the stapes in $C$. Cases of abnormal incus and stapes are shown in $E$ and $F$, respectively.

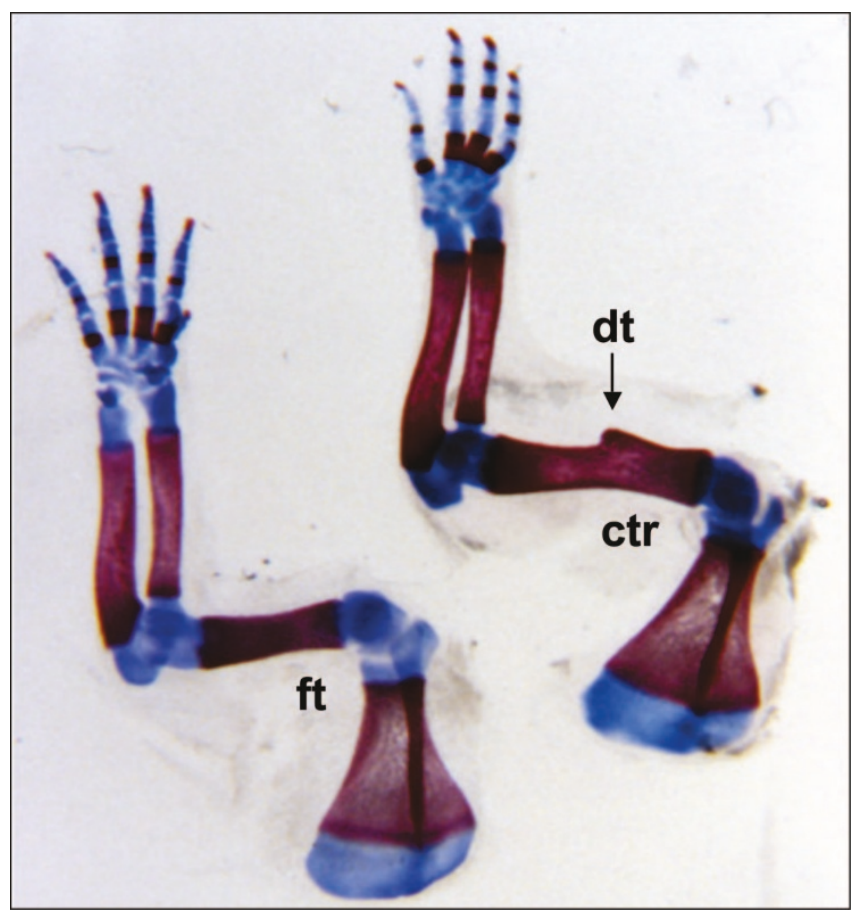

Figure 4. Left forelimbs from GD 18 control (ctr) and fluconazole-treated (ft) mouse fetuses showing missing deltoid tuberosity (dt) and shortened humerus in the fluconazole-exposed (700 mg/kg on GD 10) limb.

effects seems to correlate partly with that observed in this study. The morphologic responses observed in rodents (both rats and mice) share some similarities with the abnormal pheno-

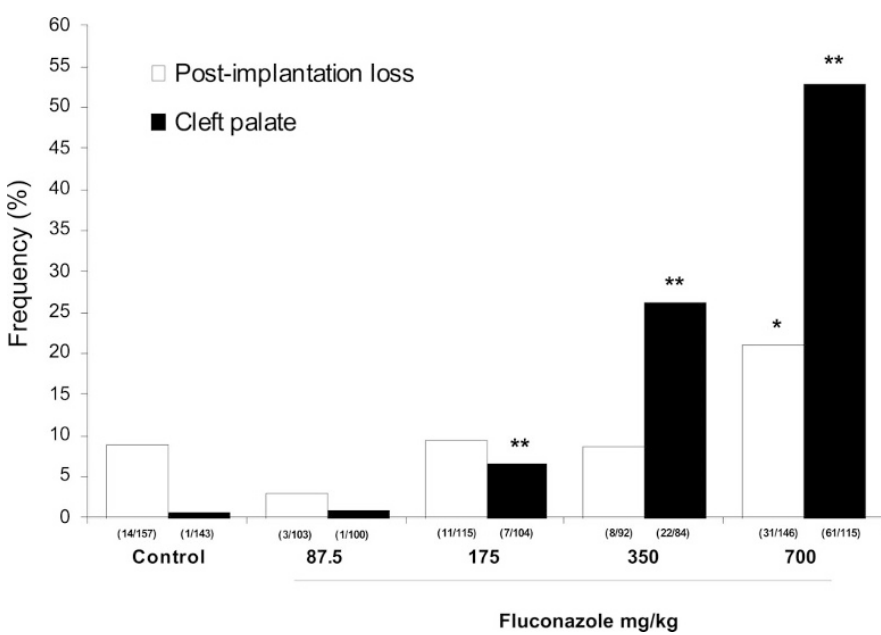

Figure 5. Effect of fluconazole on postimplantation loss and cleft palate in the ICR (CD-1) mouse (dose-response study). Fluconazole (0, 87.5, 175, 350, or $700 \mathrm{mg} / \mathrm{kg}$ ) was administered orally on GD 10. Uterine contents were evaluated on GD 18. Numbers in parentheses refer to the number of resorbed/dead fetuses of the total number of implants or to the number of affected fetuses of the total number of fetuses examined. *Statistically significant higher frequency of postimplantation loss of $700 \mathrm{mg} / \mathrm{kg}$ group (31 of 146) vs control group (14 of $157 ; p<0.05 ; \chi^{2}$ test); $* *$ statistically significant higher frequency of cleft palate $v s$ the preceding groups $\left(p<0.05 ; \chi^{2}\right.$ test). Cleft palate was observed in 1 of 143,1 of 100, 7 of 104, 22 of 84, and 61 of 115 live fetuses that were exposed to $0,87.5,175,350$, and $700 \mathrm{mg} / \mathrm{kg}$ of fluconazole. Data relative to the group that was treated with $700 \mathrm{mg} / \mathrm{kg}$ are also shown in Fig. 1 .

types described in children who are exposed in utero to high doses of fluconazole (3-5). This seems to be the instance of cleft palate; limb defects; and ear, rib, and kidney anomalies (3-5).

Dose-response analysis that was carried out during the developmental phase of maximum sensitivity identified 175 $\mathrm{mg} / \mathrm{kg}$ as the LOAEL for fluconazole-induced teratogenesis. This level of exposure is approximately seven times the maximal human therapeutic dosage (fluconazole is administered at doses up to $1600 \mathrm{mg} / \mathrm{d}$ in the treatment of disseminated fungal infections) (23). From the perspective of human risk estimation, these notions seem to favor the viewpoint that fluconazole becomes teratogenically operational only under elevated levels of exposure. However, before this assertion can be regarded as plausible, possible interspecies differences in pharmacokinetic parameters should be taken into consideration. Pharmacokinetic parameters play, in fact, a central role in establishing the amount and the form of the drug that reaches the embryonic compartment through diaplacental transfer (24). It is known that animal species can differ significantly in the rates at which they absorb, distribute, and eliminate drugs and that these differences represent a major obstacle in the extrapolation of teratologic data from laboratory animals to humans $(24,25)$. This may also be true for fluconazole. Significant differences were found when the pharmacokinetic profile of fluconazole was evaluated in mice and humans (26). Administration of a single oral dose of $1 \mathrm{mg} / \mathrm{kg}$ resulted in peak plasma concentrations that were 2-fold higher in humans than in mice (1.4 versus $0.7 \mu \mathrm{g} / \mathrm{mL})$. Other marked species differences noted were relative to the half-life $\left(t_{1 / 2}\right)$ and area under the curve (AUC), with mean values that were in both cases 5 -fold higher 
Table 3. Effect of fluconazole* on gestational parameters in the ICR (CD-1) mouse (dose-response study)

\begin{tabular}{|c|c|c|c|c|c|}
\hline & \multirow{2}{*}{$\begin{array}{l}\text { Control } \\
\text { Group } \dagger\end{array}$} & \multicolumn{4}{|c|}{ Dose $(\mathrm{mg} / \mathrm{kg})$} \\
\hline & & 87.5 & 175 & 350 & $700 \div$ \\
\hline No. of pregnant animals treated & 10 & 7 & 8 & 7 & 10 \\
\hline $\begin{array}{l}\text { No. of animals at term gestation } \\
\text { with live fetuses }\end{array}$ & 10 & 7 & 8 & 7 & 10 \\
\hline $\begin{array}{l}\text { Maternal body weight }(\mathrm{g} \pm \mathrm{SEM}) \\
\text { at term }\end{array}$ & $60.32 \pm 3.65$ & $62.47 \pm 2.89$ & $56.82 \pm 1.83$ & $61.00 \pm 1.42$ & $61.75 \pm 1.83$ \\
\hline $\begin{array}{l}\text { Maternal corrected body weight } \\
\qquad(\mathrm{g} \pm \mathrm{SEM}) \S\end{array}$ & $37.38 \pm 2.24$ & $38.49 \pm 1.22$ & $37.19 \pm 0.83$ & $39.87 \pm 0.83$ & $40.06 \pm 1.31$ \\
\hline $\begin{array}{l}\text { Gravid uterine weight at term } \\
\qquad(\mathrm{g} \pm \mathrm{SEM})\end{array}$ & $22.77 \pm 1.51$ & $23.59 \pm 1.99$ & $19.36 \pm 1.14$ & $21.13 \pm 1.41$ & $20.83 \pm 1.43$ \\
\hline Mean \pm SEM of implantations/litter & $15.70 \pm 0.67$ & $14.71 \pm 1.04$ & $14.37 \pm 0.85$ & $13.14 \pm 0.59$ & $14.60 \pm 0.56$ \\
\hline No. of implantations & 157 & 103 & 115 & 92 & 146 \\
\hline No. of live fetuses & 143 & 100 & 104 & 84 & 115 \\
\hline $\begin{array}{l}\text { Mean fetal body weight } \\
\quad(\mathrm{g} \pm \mathrm{SEM}) / \mathrm{litter}\end{array}$ & $1.23 \pm 0.05$ & $1.28 \pm 0.02$ & $1.31 \pm 0.05$ & $1.33 \pm 0.03$ & $1.34 \pm 0.04$ \\
\hline $\begin{array}{l}\text { Mean placental weight } \\
(\mathrm{g} \pm \mathrm{SEM}) / \text { litter }\end{array}$ & $0.13 \pm 0.00$ & $0.12 \pm 0.00$ & $0.11 \pm 0.00$ & $0.12 \pm 0.00$ & $0.13 \pm 0.01$ \\
\hline
\end{tabular}

* $700 \mathrm{mg} / \mathrm{kg}$ administered orally on gestational day 10 .

$\dagger$ Administered with vehicle on gestational day 10 .

$\ddagger$ Data relative to the group treated with $700 \mathrm{mg} / \mathrm{kg}$ are the same as those shown in Table 1 .

$\S$ Maternal body weight at term minus gravid uterine weight.

in humans than in mice (AUC, 43 versus $8.5 \mu \mathrm{g} \mathrm{h} / \mathrm{mL} ; t_{1 / 2}, 22$ versus $5.1 \mathrm{~h}$, respectively) (26). These differences were not apparently dependent on metabolism, because in both species, fluconazole is poorly metabolized and is mainly eliminated unchanged $(\sim 70 \%)$ in the urine (26). Plasma protein binding was comparably low (11\%) in the two species (26). Altogether, these results seem compatible with the hypothesis that fluconazole has the potential for reaching higher and more prolonged concentrations in human than in mouse embryonal tissue. Therefore, a greater understanding of interspecies pharmacokinetic differences seems to be of the utmost importance for the extrapolation of fluconazole teratogenic data from rodents to humans. An important aspect that should be examined is how the fluconazole plasma levels resulting from treatment of mice with LOAEL correlate with levels observed in humans who are treated with the therapeutic doses.

In essence, this study 1 ) analyzed the effect of developmental phase on teratogenic susceptibility to fluconazole; 2) characterized the dose-response relationship at the developmental phase of maximal sensitivity, identifying the LOAEL for fluconazole-mediated teratogenesis; and 3) expanded the current knowledge on the teratogenic spectrum induced by fluconazole by identifying novel treatment-related malformations (limb and middle ear apparatus malformations).

\section{REFERENCES}

1. Webster SW, Freeman JA 2001 Is this drug safe in pregnancy? Reprod Toxicol 15:619-629

2. Polifka JE, Friedman JM 2002 Medical genetics: 1. Clinical teratology in the age of genomics. CMAJ 167:265-273

3. Lee BE, Feinberg M, Abraham JJ, Murthy AR 1992 Congenital malformations in an infant born to a woman treated with fluconazole. Pediatr Infect Dis 11:1062-1064

4. Pursley TJ, Blomquist IK, Abraham J, Andersen HF, Bartley JA 1996 Fluconazoleinduced congenital anomalies in three infants. Clin Infect Dis 22:336-340

5. Aleck KA, Bartley DL 1997 Multiple malformation syndrome following fluconazole use in pregnancy: report of an additional patient. Am J Med Genet 72:253-256

6. Inman W, Pearce G, Wilton L 1994 Safety of fluconazole in the treatment of vaginal candidiasis. A prescription-event monitoring study, with special reference to the outcome of pregnancy. Eur J Clin Pharmacol 46:115-118
7. Mastroiacovo P, Mazzone T, Botto LD, Serafini MA, Finardi A, Caramelli L, Fusco D 1996 Prospective assessment of pregnancy outcomes after first-trimester exposure to fluconazole. Am J Obstet Gynecol 175:1645-1650

8. Jick SS 1999 Pregnancy outcomes after maternal exposure to fluconazole. Pharmacotherapy 19:221-222

9. Sorensen HT, Nielsen GL, Olesen C, Larsen H, Steffensen FH, Schonheyder HC, Olsen J, Czeizel AE 1999 Risk of malformations and other outcomes in children exposed to fluconazole in utero. Br J Clin Pharmacol 48:234-238

10. Tiboni GM 1993 Second branchial arch anomalies induced by fluconazole, a bistriazole antifungal agent, in cultured mouse embryos. Res Commun Chem Pathol Pharmacol 79:381-384

11. Menegola E, Broccia ML, Di Renzo F, Giavini E 2001 Antifungal triazoles induce malformations in vitro. Reprod Toxicol 15:421-427

12. Menegola E, Broccia ML, Di Renzo F, Giavini E 2003 Pathogenic pathways in fluconazole-induced branchial arch malformations. Birth Defects Res A Clin Mol Teratol 67:116-124

13. Menegola E, Broccia ML, Di Renzo F, Massa V, Giavini E 2004 Relationship between hindbrain segmentation, neural crest cell migration and branchial arch abnormalities in rat embryos exposed to fluconazole and retinoic acid in vitro. Reprod Toxicol 18:121-130

14. Kaufman MH, Bard JBL 1999 The Anatomical Basis of Mouse Development. Academic Press, San Diego, pp 60-76

15. Tachibana M, Noguchi Y, Monro AM 1987 Toxicology of fluconazole in experimental animals. In: Fromtling RA (ed) Recent Trends in the Discovery, Development, and Evaluation of Antifungal Agents. JR Prous, Barcelona, pp 93-102

16. Prescribing Information. Diflucan. Pfizer, New York, 2003

17. Inouye M 1976 Differential staining of cartilage and bone in fetal mouse skeleton by Alcian blue and alizarin red S. Cong Anom 16:171-173

18. Kimmel CA, Trammel C 1981 A rapid procedure for routine staining of cartilage and bone in fetal and adult animals. Stain Technol 56:271-273

19. Kuczuk MJ, Scott WJ 1984 Potentiation of acetazolamide-induced ectrodactyly in SWV and C57/BL mice by cadmium sulphate. Teratology 29:427-435

20. Wilson JC 1965 Methods for administering agents and detecting malformations in experimental animals. In: Wilson JG, Warkany J (eds) Teratology: Principles and Techniques. University of Chicago Press, Chicago, pp 262-277

21. Mallo M, Gridley T 1996 Development of the mammalian ear: coordinate regulation of formation of the tympanic ring and the external acoustic meatus. Development 122:173-179

22. Mallo M 2001 Formation of the middle ear: recent progress on the developmental and molecular mechanisms. Dev Biol 231:410-419

23. Debruyne D 1997 Clinical pharmacokinetics of fluconazole in superficial and systemic mycoses. Clin Pharmacokinet 33:52-77

24. Committee on Developmental Toxicology, Board on Environmental Studies and Toxicology, Commission on Life Sciences, National Research Council 2000 Scientific Frontiers in Developmental Toxicology and Risk Assessment, National Academy Press, Washington DC, pp 58-84

25. Brent RL 2004 Utilization of animal studies to determine the effects and human risks of environmental toxicants (drugs, chemicals, and physical agents). Pediatrics 113:984-995

26. Humphrey MJ, Jevons S, Tarbit MH 1985 Pharmacokinetic evaluation of UK-49,858, a metabolically stable triazole antifungal drug, in animals and humans. Antimicrob Agents Chemother 28:648-53 